\title{
Erratum to: Systemic lupus erythematosus after thymectomy for myasthenia gravis: a case report and review of the literature
}

\author{
Hyder A. Omar • Mohammed A. Alzahrani • Ali A. A. Al bshabshe • \\ Alhussain Assiri - Medhat Shalaby • Ahmad Dwedar • Saad Rezk Abdulwahed • \\ Mahmoud Rezk-Abd-Elwahed Hussein
}

Published online: 9 April 2010

(C) Japanese Society of Nephrology 2010

\section{Erratum to: Clin Exp Nephrol}

DOI 10.1007/s10157-009-0256-5

The authors' affiliations appeared incorrectly in the article cited above. The correct affiliations are as follows:

H. A. Omar - M. A. Alzahrani - A. A. A. Al bshabshe .

A. Assiri - M. Shalaby · A. Dwedar

Department of Medicine, College of Medicine, King Khalid University and Asser Central Hospital, Abha, Kingdom of Saudi Arabia

The online version of the original article can be found under doi:10.1007/s10157-009-0256-5.

H. A. Omar - M. A. Alzahrani - A. A. A. Al bshabshe .

A. Assiri - M. Shalaby · A. Dwedar Department of Medicine, College of Medicine,

King Khalid University and Asser Central Hospital,

Abha, Kingdom of Saudi Arabia

S. R. Abdulwahed

Radiology Department, Faculty of Medicine,

Al-Azhar University, Assuit, Egypt

M. R. Hussein $(\square)$

Department of Pathology, Faculty of Medicine,

Assuit University, Assuit, Egypt

e-mail: mrcpath17@gmail.com; mrh17@gawab.com

Present Address:

M. R. Hussein

Pathology Department, Asser Central Hospital,

Abha, Kingdom of Saudi Arabia 